Journal of Computer Science 6 (8): 912-919, 2010

ISSN 1549-3636

C 2010 Science Publications

\title{
Rehabilitation of a Human Arm Supported by a Robotic Manipulator: A Position/Force Cooperative Control
}

\author{
Haifa Mehdi and Olfa Boubaker \\ Department of Physical Engineering and Instrumentation, \\ National Institute of Applied Sciences and Technology, University of Carthage, \\ INSAT, Centre Urbain Nord BP 676-1080 Tunis Cedex, Tunisia
}

\begin{abstract}
Problem statement: The assistance of person with limited ability of arm movement is necessary for rehabilitation reasons. This aid is required not only to cover the human performances of the arm in motion and force but also to have a strictly stable dynamics. In this study, we proposed a cooperative system between a disabled arm and a robotic manipulator to reach such objectives. Desired positions and contact forces were imposed by the disabled human whereas appropriate torques were applied by the manipulator to follow human intension. Approach: Various control strategies were proposed during recent years to solve position/force control problem. The impedance control concept was used in this study. A relationship between the dynamics of the robot and its energy was developed to derive stability conditions of the robotic system at the constrained motion phase using a suitable Lyapunov approach. Results: New sufficient conditions of asymptotic stability were developed. To prove the efficiency of the proposed approach, a prototype of a human arm coupled to cooperative constrained robotic manipulator was used. The simulation results showed the stability and the performances of the proposed approach. Conclusion: Results showed the possibility of their use in a real context of rehabilitation of injured and disabled people.
\end{abstract}

Key words: Human arm, impedance control, constrained robotic systems, Lyapunov approach

\section{INTRODUCTION}

In recent years, many efforts have been devoted to develop systems that can help people with limited movement or rehabilitate injuries and disabilities. In this context, many technologies have been introduced through proposed robotic devices that are attached to limbs of human body to maintain or improve their functions of movement in constrained environment (Papageorgiou et al., 2006; Soichi et al., 2008; Ikeura and Inooka, 1995). Position/force control of constrained robotic systems can be then considered as a very important issue in the field of human rehabilitation.

Various control strategies are proposed during recent years to solve position/force problems. These studies were first introduced by Ferrell and Sheridan (1967) and leads to an extensive bibliography. The handbook of Siciliano and Khatib (2008), the books of Fu et al. (1987), Siciliano and Villani (1999); Canudas de Wit et al. (1996) and Khalil and Dombre (2002), the surveys of Whitney (1987); Patarinski and Botev (1993); Volpe and Khosla (1995); Zeng and Hemami (1997);
De Schutter et al. (1998); Chiaverini et al. (1999) and Yoshikawa (2000) reveal the wealth, development and maturity of this field.

According to the control goal, force/position control algorithms can be categorized into three classes: (1) Force/position control based in desired dynamic relationship between the end-effector position and the contact force including stiffness control that involves a relation between position and applied force (Salisbury, 1980) and impedance control involving the relation between velocity and applied force (Hogan, 1985). (2) Simultaneously position/force control including hybrid position/force control (Yoshikawa, 2003; Raibert and Craig, 1981). (3) Parallel position/force control (Chiaverini and Sciavicco, 1993; Siciliano and Villani, 2000).

When the robot is constrained to the environment it is possible that instable behavior occur. So, to find stability conditions for robotic systems in contact with the environment, many researchers used linearized models (Karunakar and Goldenberg, 1988; Lawrence,

Corresponding Author: Olfa Boubaker, Department of Physical Engineering and Instrumentation,

National Institute of Applied Sciences and Technology, University of Carthage, INSAT,

Centre Urbain Nord BP 676-1080 Tunis Cedex, Tunisia

912 
1988). Further analyses are done on the basis of nonlinear models and generally use Lyapunov approaches. However they generally require very hard developments (Chiaverini et al., 1994) or need decoupling between the position and force control (Yabuta et al., 1988).

In this study, we present an improved proof of asymptotic stability of constrained robotic systems based on the Lyapunov method using a relationship between the dynamics of the robot and its energy. The proposed approach is an enough straightforward Lyapunov approach without force and position control separation. This result is applied on a robotic manipulator which is attached to a human arm.

\section{MATERIALS AND METHODS}

The rehabilitation cooperative system: The rehabilitation system is composed of a $2 \mathrm{DOF}$ planar robotic system which is attached to the disabled human arm as seen in Fig. 1. To reach rehabilitation objectives, desired positions and contact forces are imposed by the disabled human whereas appropriate torques must be applied by the robotic system to follow human intension.

The human arm: The human arm parameters are shown in Table 1 (Aloulou and Boubaker, 2010). For $i=1,2$, the inertia parameters are computed by the well known relation $I_{i}=\frac{m_{i} L_{i}^{2}}{12}$.

Table 1: Human arm parameters

\begin{tabular}{lllll}
\hline Bodies & $\mathrm{m}_{\mathrm{i}}(\mathrm{Kg})$ & $\mathrm{L}_{\mathrm{i}}(\mathrm{m})$ & $\mathrm{k}_{\mathrm{i}}(\mathrm{m})$ & $\mathrm{I}_{\mathrm{i}}\left(\mathrm{Kg} \mathrm{m}^{-2}\right)$ \\
\hline Arm & 1.960 & 0.321 & 0.140 & 0.016 \\
Forearm & 1.120 & 0.253 & 0.109 & 0.006 \\
\hline
\end{tabular}

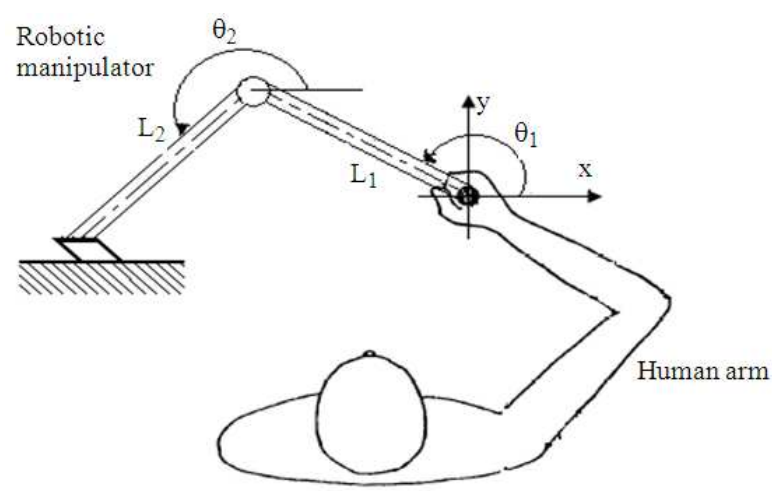

Fig. 1: A robotic manipulator attached to a human arm
The parameters $m_{i}, L_{i}$ and $k_{i}$ design mass, length and position of gravity center of the right arm and forearm of a human person, respectively. Desired contact forces are imposed by the human whereas appropriate torques are applied by the manipulator to follow human intension as shown in Fig. 2.

The robotic manipulator: The manipulator is a Two planar Degrees Of Freedom (2DOF) robot. The robot arm has the same parameters as the human arm. Its endeffector position $\mathrm{X}=(\mathrm{x}, \mathrm{y})$ and velocity $\dot{\mathrm{X}}=(\dot{\mathrm{x}}, \dot{\mathrm{y}})$ are respectively computed using the direct kinematic models:

$$
\left\{\begin{array}{l}
x=L_{1} \cos \theta_{1}+L_{2} \cos \theta_{2} \\
y=L_{1} \sin \theta_{1}+L_{2} \sin \theta_{2}
\end{array}\right.
$$

and

$$
\dot{\mathrm{X}}=\mathrm{J}(\theta) \dot{\theta}
$$

where, $J(\theta) \in R^{n \times n}$ is the Jacobian matrix given by:

$$
J(\theta)=\left[\begin{array}{cc}
-L_{1} \sin \theta_{1} & -L_{2} \sin \theta_{2} \\
\mathrm{~L}_{1} \cos \theta_{1} & \mathrm{~L}_{2} \cos \theta_{2}
\end{array}\right]
$$

The dynamical model of a constrained robotic system is described by the following equation (Chiaverini et al., 1999):

$$
\mathrm{M}(\theta) \ddot{\theta}+\mathrm{H}(\theta, \dot{\theta})+\mathrm{G}(\theta)=\mathrm{U}-\mathrm{J}^{\mathrm{T}}(\theta) \mathrm{F}
$$

Where:

$$
\begin{aligned}
\theta, \dot{\theta}, \ddot{\theta} \in \mathrm{R}^{\mathrm{n}}= & \text { Joint position, velocity and acceleration } \\
& \text { vectors respectively } \\
\mathrm{M}(\theta) \in \mathrm{R}^{\mathrm{n}}= & \text { The inertia matrix } \\
\mathrm{H}(\theta, \dot{\theta}) \in \mathrm{R}^{\mathrm{n}}= & \text { The vector of centrifugal and Coriolis } \\
& \text { forces } \\
\mathrm{G}(\theta) \in \mathrm{R}^{\mathrm{n}}= & \text { The vector of gravity terms } \\
\mathrm{U} \in \mathrm{R}^{\mathrm{n}}= & \text { The generalized joint force vector } \\
\mathrm{F} \in \mathrm{R}^{\mathrm{n}}= & \text { The vector of contact generalized forces } \\
& \text { exerted by the manipulator on the } \\
& \text { environment }
\end{aligned}
$$
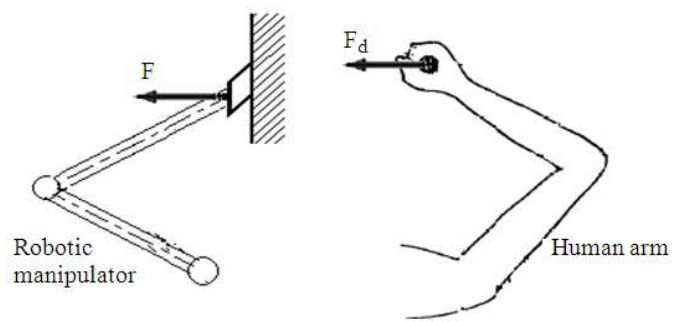

Fig. 2: Desired forces imposed by a human arm 
The different matrices of the dynamic model are given by:

$$
\begin{aligned}
& \mathrm{M}(\theta)=\left[\begin{array}{cc}
\mathrm{I}_{1}+\mathrm{m}_{1} \mathrm{k}_{1}^{2}+\mathrm{m}_{2} \mathrm{~L}_{1}^{2} & \mathrm{~m}_{2} \mathrm{~L}_{1} \mathrm{k}_{2} \cos \left(\theta_{1}-\theta_{2}\right) \\
\mathrm{m}_{2} \mathrm{~L}_{1} \mathrm{k}_{2} \cos \left(\theta_{1}-\theta_{2}\right) & \mathrm{I}_{2}+\mathrm{m}_{2} \mathrm{k}_{2}^{2}
\end{array}\right] \\
& \mathrm{H}(\theta, \dot{\theta})=\left[\begin{array}{cc}
0 & \mathrm{~m}_{2} \mathrm{~L}_{1} \mathrm{k}_{2} \sin \left(\theta_{1}-\theta_{2}\right) \\
-\mathrm{m}_{2} \mathrm{~L}_{1} \mathrm{k}_{2} \sin \left(\theta_{1}-\theta_{2}\right) & 0
\end{array}\right]\left[\begin{array}{c}
\dot{\theta}_{1}^{2} \\
\dot{\theta}_{2}^{2}
\end{array}\right] \\
& \mathrm{G}(\theta)=\mathrm{g}\left[\begin{array}{c}
\left(\mathrm{m}_{1} \mathrm{~L}_{1}+\mathrm{m}_{1} \mathrm{k}_{1}\right) \cos \theta_{1} \\
\mathrm{~m}_{2} \mathrm{k}_{2} \cos \theta_{2}
\end{array}\right]
\end{aligned}
$$

The position/force controller: Impedance control design, that will be used to solve the position/force control problem, is based on the following concept: the controller ensures desired impedance dynamics while regulates position in all directions (Hogan, 1985). The desired impedance is defined by:

$Z_{d}=\frac{F_{d}-F}{X_{d}-X}$

where, $X_{d}$ and $F_{d}$ are desired Cartesian position and desired contact force. It is generally required that the desired impedance verifies:

$Z_{d}=K_{d}+B_{d} s+M_{d} s^{2}$

$\mathrm{K}_{\mathrm{d}}, \mathrm{B}_{\mathrm{d}}, \mathrm{M}_{\mathrm{d}} \in \mathrm{R}^{\mathrm{n} \times \mathrm{n}}$ are desired stiffness, damping and inertia matrices and $\mathrm{S}$ is the Laplace operator. Substituting (4) in (5) gives:

$\mathrm{F}_{\mathrm{d}}-\mathrm{F}=\mathrm{K}_{\mathrm{d}}\left(\mathrm{X}_{\mathrm{d}}-\mathrm{X}\right)+\mathrm{B}_{\mathrm{d}}\left(\dot{\mathrm{X}}_{\mathrm{d}}-\dot{\mathrm{X}}\right)+\mathrm{M}_{\mathrm{d}}\left(\ddot{\mathrm{X}}_{\mathrm{d}}-\ddot{\mathrm{X}}\right)$

$\mathrm{X}, \dot{\mathrm{X}}, \ddot{\mathrm{X}} \in \mathrm{R}^{\mathrm{n}}$ are Cartesian end-effector position, velocity and acceleration respectively. The block diagram of the entire control system is shown by the Fig. 3 (Hogan, 1984). $X=f_{g}(\theta)$ is the direct kinematic model of the constrained robotic system.

$\mathrm{K}_{\mathrm{p}}, \mathrm{K}_{\mathrm{v}}, \mathrm{K}_{\mathrm{f}} \in \mathrm{R}^{\mathrm{n} \times \mathrm{n}}$ are position, velocity and force gain matrices respectively. Based on Fig. 3, the control law is then given by:

$$
\mathrm{U}=\mathrm{J}^{\mathrm{T}}\left[\mathrm{K}_{\mathrm{p}}\left(\mathrm{X}_{\mathrm{d}}-\mathrm{X}\right)+\mathrm{K}_{\mathrm{v}}\left(\dot{\mathrm{X}}_{\mathrm{d}}-\dot{\mathrm{X}}\right)+\mathrm{K}_{\mathrm{f}}\left(\mathrm{F}_{\mathrm{d}}-\mathrm{F}\right)+\mathrm{F}_{\mathrm{d}}\right]+\mathrm{G}
$$

Position/force problem: Design a control law $\mathrm{U} \in \mathrm{R}^{\mathrm{n}}$ under a force law $\mathrm{F} \in \mathrm{R}^{\mathrm{n}}$ that satisfied asymptotic stability of the constrained robotic system described by the dynamical model (3) and the kinematic model (2).

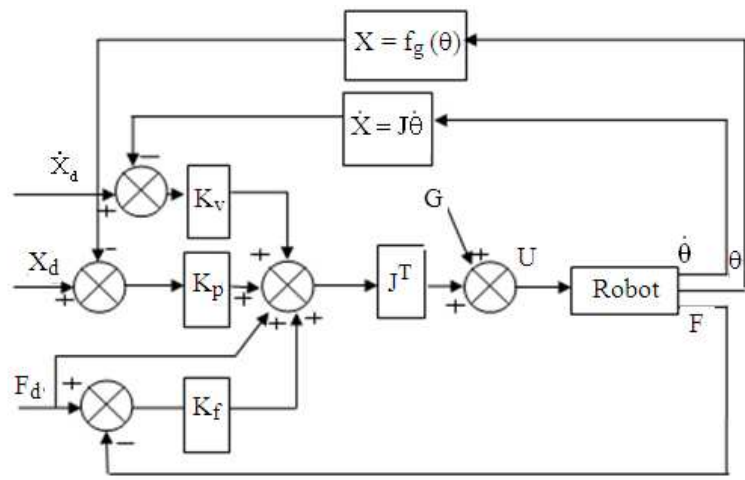

Fig. 3: Impedance controller

The last problem will be solved under the following assumptions:

Assumption 1: The entire vectors of force, position and velocity are measured.

Assumption 2: All feedback gains, used to solve the control problem are diagonal matrix with equal elements.

Assumption 3: The constrained environment of the robotic system is static.

\section{RESULTS}

Relationship between the dynamics of the constrained robotic system and its energy: Let $\Phi$ and $\mathrm{Y}(\Phi)$ the errors in the joint and task space of the constrained robotic system defined respectively by:

$\Phi=\theta-\theta_{\mathrm{d}}$

$\mathrm{Y}(\Phi)=\mathrm{X}(\theta)-\mathrm{X}_{\mathrm{d}}$

Consider the constrained robot system described by the dynamic model (3) for the force design (6) and the control law (7). Using the relations (8) and (9) we can write:

$$
\begin{aligned}
& \mathrm{M}(\Phi) \ddot{\Phi}+\mathrm{H}(\Phi, \dot{\Phi})+\mathrm{J}^{\mathrm{T}}(\Phi) \mathrm{K}_{1} \mathrm{Y}(\Phi) \\
& +\mathrm{J}^{\mathrm{T}}(\Phi) \mathrm{K}_{2} \dot{\mathrm{Y}}(\Phi)+\mathrm{J}^{\mathrm{T}}(\Phi) \mathrm{K}_{3} \ddot{\mathrm{Y}}(\Phi)=0
\end{aligned}
$$

Where:

$$
\begin{aligned}
& \mathrm{K}_{1}=\mathrm{K}_{\mathrm{p}}+\left(\mathrm{I}+\mathrm{K}_{\mathrm{f}}\right) \mathrm{K}_{\mathrm{d}} \\
& \mathrm{K}_{2}=\mathrm{K}_{\mathrm{v}}+\left(\mathrm{I}+\mathrm{K}_{\mathrm{f}}\right) \mathrm{B}_{\mathrm{d}} \\
& \mathrm{K}_{3}=\left(\mathrm{I}+\mathrm{K}_{\mathrm{f}}\right) \mathrm{M}_{\mathrm{d}}
\end{aligned}
$$


Recall that the Lagrange equation of a constrained robotic system is described by (Yabuta et al., 1988):

$\frac{\mathrm{d}}{\mathrm{dt}}\left(\frac{\partial \mathrm{T}}{\partial \dot{\Phi}}\right)-\frac{\partial \mathrm{T}}{\partial \Phi}+\frac{\partial \mathrm{P}}{\partial \Phi}+\frac{\partial \mathrm{D}}{\partial \dot{\Phi}}=0$

$\mathrm{T}(\Phi, \dot{\Phi})$ is the kinetic energy of the constrained robotic system (3) defined by:

$\mathrm{T}(\Phi, \dot{\Phi})=\frac{1}{2} \dot{\Phi}^{\mathrm{T}} \mathrm{M}(\Phi) \dot{\Phi}$

$\mathrm{P}(\Phi), \mathrm{D}(\Phi, \dot{\Phi})$ are potential energy and dissipation function respectively. We can show that (Mehdi and Boubaker, 2010):

$\frac{\partial \mathrm{P}}{\partial \Phi}=\mathrm{J}^{\mathrm{T}}(\Phi) \mathrm{K}_{1} \mathrm{Y}(\Phi)$

$\frac{\partial \mathrm{D}}{\partial \dot{\Phi}}=\mathrm{J}^{\mathrm{T}}(\Phi) \mathrm{K}_{2} \dot{\mathrm{Y}}(\Phi)+\mathrm{J}^{\mathrm{T}}(\Phi) \mathrm{K}_{3} \ddot{\mathrm{Y}}(\Phi)$

$\mathrm{H}(\Phi, \dot{\Phi})=\sum\left(\frac{\mathrm{d} \Phi_{\mathrm{i}}}{\mathrm{dt}} \frac{\partial \mathrm{M}}{\partial \Phi_{\mathrm{i}}}\right) \frac{\dot{\Phi}}{2}$

New sufficient stability conditions: Impose to the system (10) to have a Lyapunov Hamiltonian function defined by (Yabuta et al., 1988):

$\mathrm{V}(\Phi, \dot{\Phi})=\mathrm{T}(\Phi, \dot{\Phi})+\mathrm{P}(\Phi)-\mathrm{P}(0)$

The error dynamics (10) are asymptotically stable if $\mathrm{V}(\Phi, \dot{\Phi})$ satisfies the following conditions (Slotine and $\mathrm{Li}, 1991)$ :

$\mathrm{V}(0,0)=0$ if $\Phi=0, \dot{\Phi}=0$

$\mathrm{V}(\Phi, \dot{\Phi})>0$ if $\Phi \neq 0, \dot{\Phi} \neq 0$

$\dot{\mathrm{V}}(\Phi, \dot{\Phi})<0$ if $\Phi \neq 0, \dot{\Phi} \neq 0$

Theorem: For desired matrices $\mathrm{K}_{\mathrm{d}}, \mathrm{B}_{\mathrm{d}}, \mathrm{M}_{\mathrm{d}} \in \mathrm{R}^{\mathrm{n} \times \mathrm{n}}$ and if there exist diagonal matrices $K_{p}, K_{v}, K_{f} \in R^{n \times n}$ such that the following conditions:

$\left\{\begin{array}{l}\mathrm{K}_{\mathrm{p}}+\left(\mathrm{I}+\mathrm{K}_{\mathrm{f}}\right) \mathrm{K}_{\mathrm{d}}>0 \\ \mathrm{~K}_{\mathrm{v}}+\left(\mathrm{I}+\mathrm{K}_{\mathrm{f}}\right) \mathrm{B}_{\mathrm{d}}>0 \\ \mathrm{M}_{\mathrm{d}}=0\end{array}\right.$ or

$\left\{\begin{array}{l}\mathrm{K}_{\mathrm{p}}>0 \\ \mathrm{~K}_{\mathrm{v}}>0 \\ \mathrm{~K}_{\mathrm{f}}=-\mathrm{I}\end{array}\right.$

are satisfied, then the system described by (2) and (3) is asymptotically stable under the force model described by:

$\mathrm{F}=\mathrm{F}_{\mathrm{d}}-\mathrm{K}_{\mathrm{d}}\left(\mathrm{X}_{\mathrm{d}}-\mathrm{X}\right)-\mathrm{B}_{\mathrm{d}}\left(\dot{\mathrm{X}}_{\mathrm{d}}-\dot{\mathrm{X}}\right)-\mathrm{M}_{\mathrm{d}}\left(\ddot{\mathrm{X}}_{\mathrm{d}}-\ddot{\mathrm{X}}\right)$

and the control law:

$\mathrm{U}=\mathrm{J}^{\mathrm{T}}\left[\mathrm{K}_{\mathrm{p}}\left(\mathrm{X}_{\mathrm{d}}-\mathrm{X}\right)+\mathrm{K}_{\mathrm{v}}\left(\dot{\mathrm{X}}_{\mathrm{d}}-\dot{\mathrm{X}}\right)+\left(\mathrm{K}_{\mathrm{f}}+\mathrm{I}\right) \mathrm{F}_{\mathrm{d}}-\mathrm{K}_{\mathrm{f}} \mathrm{F}\right]+\mathrm{G}$

Proof: See (Mehdi and Boubaker, 2010)

Simulations: Stability conditions (21) are tested on the rehabilitation cooperative system shown by Fig. 1. Numerical parameters of the constrained robotic system are those of the human arm exposed in Table 1 . We adopt, for the control and force laws (23) and (24) the following numerical values:

$$
\begin{aligned}
& \mathrm{K}_{\mathrm{d}}=\operatorname{diag}\left[\begin{array}{ll}
10 & 10
\end{array}\right], \mathrm{B}_{\mathrm{d}}=\operatorname{diag}\left[\begin{array}{ll}
5 & 5
\end{array}\right], \mathrm{K}_{\mathrm{p}}=\operatorname{diag}\left[\begin{array}{ll}
10^{3} & 10^{3}
\end{array}\right] \\
& \mathrm{K}_{\mathrm{v}}=\operatorname{diag}\left[\begin{array}{ll}
30 & 30
\end{array}\right], \mathrm{K}_{\mathrm{f}}=\operatorname{diag}\left[\begin{array}{ll}
20 & 20
\end{array}\right]
\end{aligned}
$$

The desired positions and forces are chosen as follows: $X_{d}=\left[\begin{array}{ll}0.25 & 0\end{array}\right]^{\mathrm{T}}, \mathrm{F}_{\mathrm{d}}=\left[\begin{array}{ll}0 & 5\end{array}\right]^{\mathrm{T}}$. Figure 4-7 show that desired positions and forces are followed respectively whereas Fig. 8 prove that control laws are smooth and realizable.

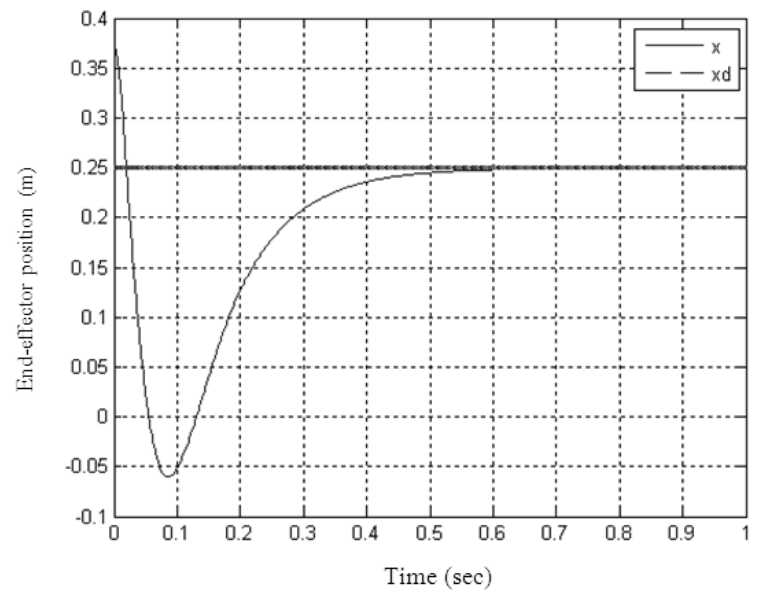

Fig. 4: End-effector position in the $\mathrm{x}$ axis 


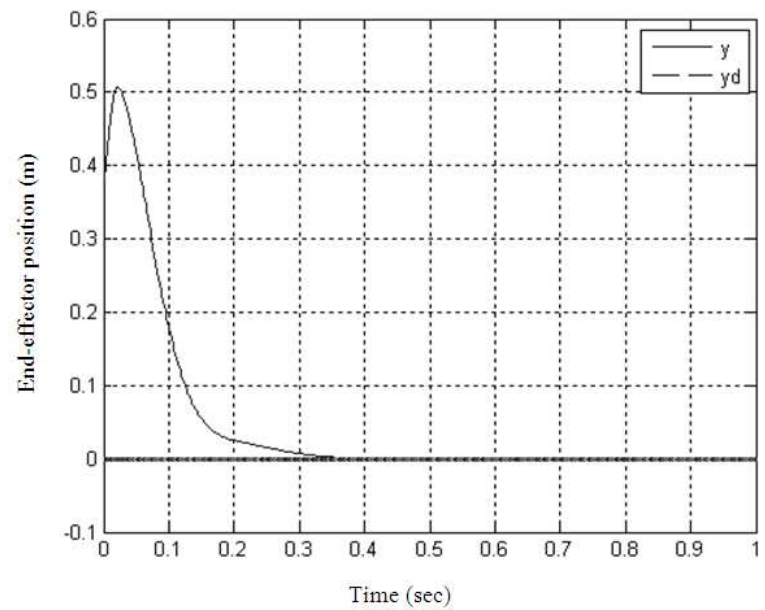

Fig. 5: End-effector position in the y axis

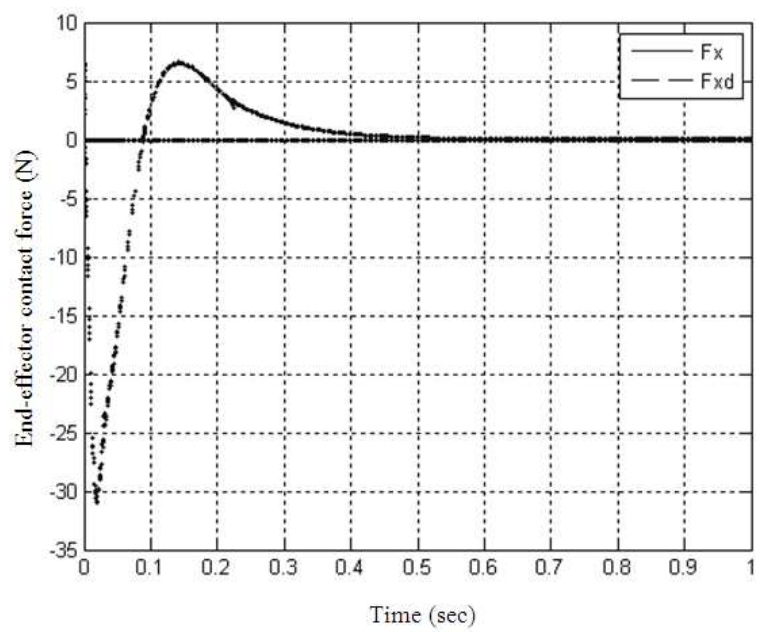

Fig. 6: Contact force response in the $\mathrm{x}$ axis

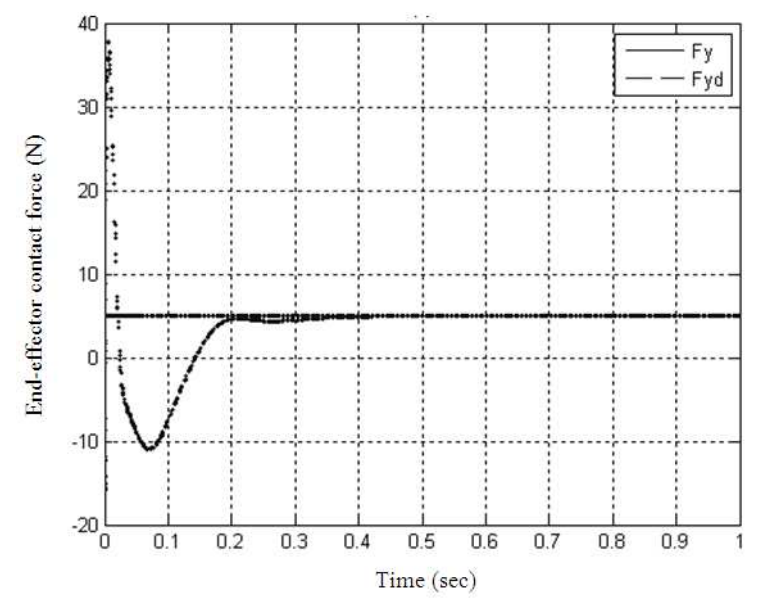

Fig. 7: Contact force response in the y axis

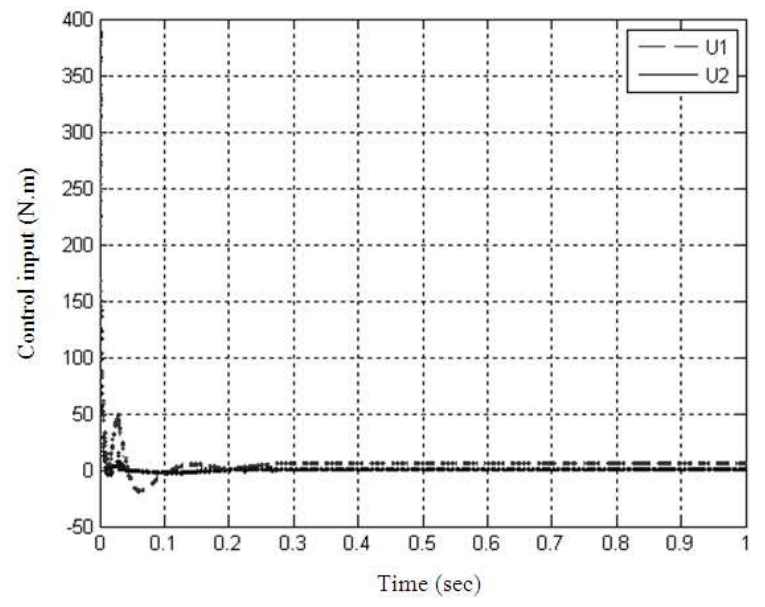

Fig. 8: Control laws

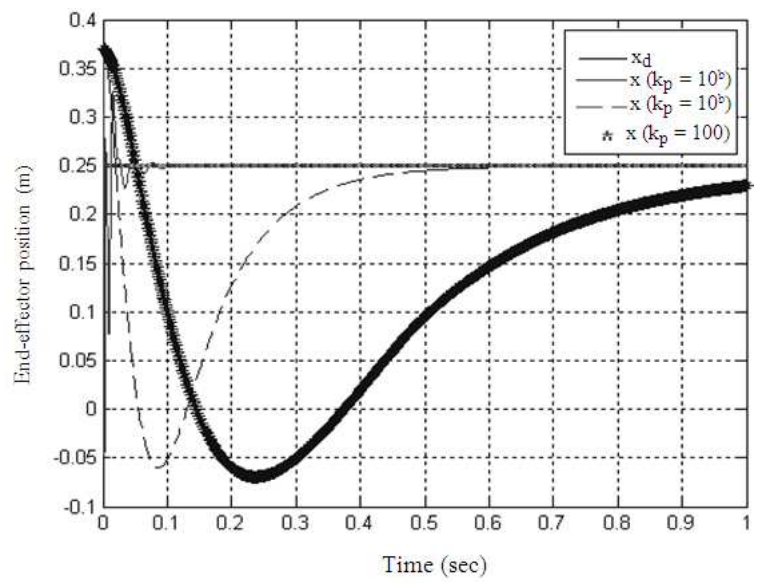

Fig. 9: Gain position $\mathrm{K}_{\mathrm{p}}$ effect on the end-effector position in the $\mathrm{x}$ axis

\section{DISCUSSION}

To reveal the effect of tuning parameters $k_{p}, k_{v}, k_{f}$ and $\mathrm{B}_{\mathrm{d}} \mathrm{K}_{\mathrm{d}}^{-1}$ on the dynamics of the controlled system we have performed different simulations. Figure 9 and 10 show the effect of the position gain $\mathrm{K}_{\mathrm{p}}$ and the velocity gain $\mathrm{K}_{\mathrm{v}}$ respectively on the dynamics of the Cartesian positions whereas Fig. 11 proves the effect of the force gain $\mathrm{K}_{\mathrm{f}}$ on the contact force responses.

Figure 12 and 13 illustrate the effect of the pole assignment of the transfer function $1 / Z_{d}(s)$ on the end-effector position and contact force respectively. To improve the adaptability of constrained robotic system to its environment, it is clear that an appropriate selection of the tuning parameters $\mathrm{K}_{\mathrm{p}}, \mathrm{K}_{\mathrm{v}}, \mathrm{K}_{\mathrm{f}}$ and 


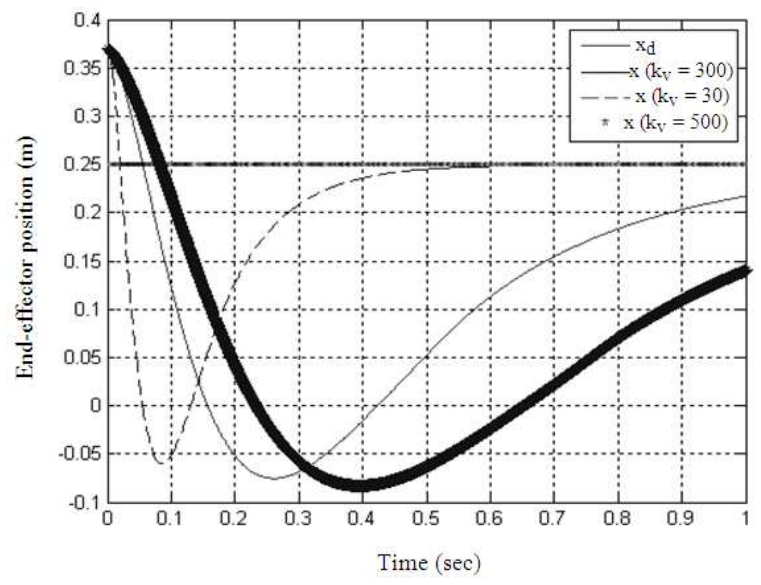

Fig. 10: Gain velocity $K_{v}$ effect on end-effector position in the $\mathrm{x}$ axis

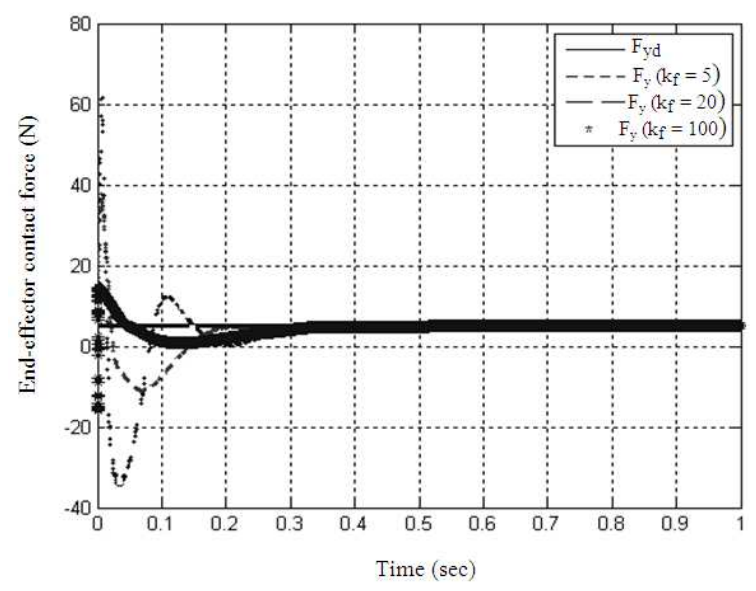

Fig. 11: Gain force $K_{f}$ effect on end-effector contact force in the $\mathrm{y}$ axis

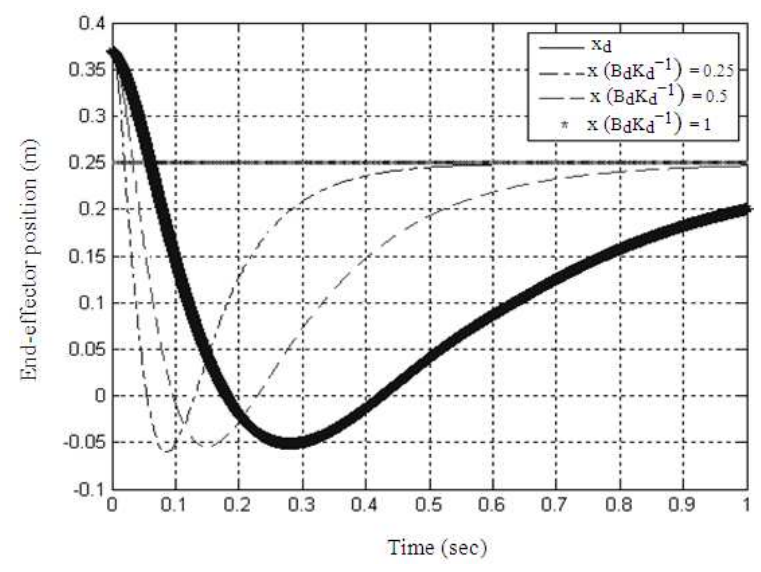

Fig. 12: Pole assignment effect of the transfer function on the end-effector position in the $\mathrm{x}$ axis

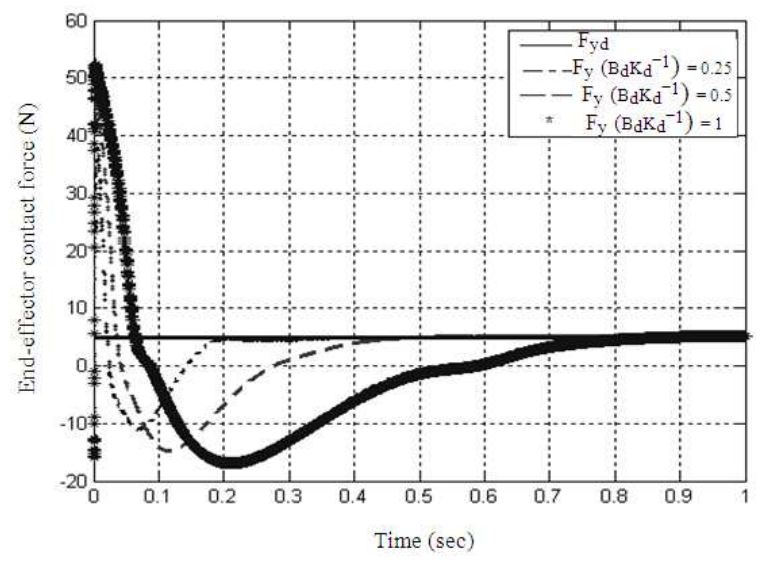

Fig. 13: Pole assignment effect of the transfer function $1 / Z_{d}(s)$ on contact force in the $y$ axis

$\mathrm{B}_{\mathrm{d}} \mathrm{K}_{\mathrm{d}}^{-1}$ must be achieved to find a compromise between fast transit response and low overshoot of state variables and control laws. By the proposed approach, the controlled system can achieve high accuracy, not only on the position and force but also achieve high speed response.

\section{CONCLUSION}

In this study, the problem of rehabilitation of disabled people arm was discussed using a cooperative constrained robotic manipulator. A position force control approach is applied to the robotic system attached to the human arm to follow the human intention of movement. The considered approach was achieved using Lyapunov theory and proposes new sufficient conditions of stability to the cooperative system. Simulation results confirmed the effectiveness and performance of our method. Discussions are presented around improvement of the adaptability of the rehabilitation robotic device attached to the human arm to its environment and enhancement of its dynamical response via a suitable selection of tuning parameters of the planned control and force laws which can be achieved in future study by computational intelligent tools.

\section{REFERENCES}

Aloulou, G.A. and O. Boubaker, 2010. Modeling and controlling a humanoid robot in the three dimensional space. Proceeding of the IEEE International Symposium on Robotics and Intelligent Sensors, Mar. 8-11, IEEE Robotic and Automation Society, Nogoya University, Japan, pp: 376. 
Canudas, de Wit, C., B. Siciliano and G. Bastin, 1996. Theory of Robot Control. 1st Edn., Spring-Verlag, London, Great Britain, ISBN: 3540760547, pp: 392.

Chiaverini, S. and L. Sciavicco, 1993. The parallel approach to force/position control of robotic manipulators. IEEE Trans. Robot. Automat., 9: 361-373. DOI: 10.1109/70.246048

Chiaverini, S., B. Siciliano and L. Villani, 1994. Force/position regulation of compliant robot manipulators. IEEE Trans. Autom. Control, 39: 647-652. DOI: 10.1109/9.280780

Chiaverini, S., B. Siciliano and L. Villani, 1999. A survey of robot interaction control schemes with experimental comparison. IEEE/ASME Trans. Mechatron., 4: 273-285. DOI: 10.1109/3516.789685

De Schutter, J., H. Bruyninckx, W.H. Zhu and M.W. Spong, 1998. Force Control: A Bird's Eye View. In: Control Problems in Robotics and Automation, Siciliano and Valavanis (Eds.). Springer, London UK, pp: 295.

Ferrell, W.R. and T.B. Sheridan, 1967. Supervisory control of remote manipulators. IEEE Spect., 4: 81-88. DOI: 10.1109/MSPEC.1967.5217126

Fu, K.S., R.C. Gonzalez and C.S. Lee, 1987. Robotics: Control, Sensing, Vision and Intelligence. 1st Edn., McGraw-Hill, New York, ISBN 10: 0070226253, pp: 580.

Hogan, N., 1984. Impedance control of industrial robots. Robot. Comput. Integ. Manufact., 1: 97-113.

Hogan, N., 1985. Impedance control: An approach to manipulators: Part 1, 2, 3. ASME J. Dyn. Syst. Measure. Control, 107: 1-24.

Karunakar, S.B. and A.A. Goldenberg, 1988. Contact stability in model-based force control systems of robot manipulators. Proceeding of the IEEE International Symposium on Intelligent Control, Aug. 24-26, IEEE Computer Society, Arlington, VA, pp: 412-417. DOI: 10.1109/ISIC.1988.65467

Khalil, W. and E. Dombre, 2002. Modeling, Identification and Control of Robots. 2nd Edn., Hermes, France, ISBN: 2746200031, pp: 495.

Lawrence, D.A., 1988. Impedance control stability properties in common implementation. Proceeding of the IEEE International Conference on Robotics and Automation, Apr. 24-29, IEEE Computer Society, Philadelphia, PA, pp: 1185-1190. DOI: 10.1109/ROBOT.1988.12222

Mehdi, H. and O. Boubaker, 2010. Position/force control for constrained robotic systems: A Lyapunov approach. Proceeding of the IEEE International Symposium on Robotics and Intelligent Sensors, Mar. 8-11, IEEE Robotic and Automation Society, Nogoya University, Japan, pp: 376.
Patarinski, S.P and R. Botev, 1993. Robot force control: A review. Mechatronics, 3: 377-398. DOI: 10.1016/0957-4158(93)90012-Q

Papageorgiou, X., J. McIntyre and K.J. Kyriakopoulos, 2006. Towards recognition of control variables for an exoskeleton. Proceeding of the IEEE International Symposium of Intelligent Control, Oct. 4-6, IEEE Computer Society, Munich, pp: 3053-3058. DOI: 10.1109/CACSD-CCAISIC.2006.4777125

Raibert, M. and J.J. Craig, 1981. Hybrid position/force control of manipulators. ASME J. Dyn. Syst., Measure. $\quad$ Control, 120: 126-133. http://me.queensu.ca/courses/MECH850/references /projectbyraibert.pdf

Ikeura, R. and H. Inooka, 1995. Variable impedance control of a robot for cooperation with a human. Proceeding of the IEEE international Conference on Robotics and Automation, May 21-27, IEEE Computer Society, Nagoya, Japan, pp: 3097-3102. DOI: 10.1109/ROBOT.1995.525725

Salisbury, J.K., 1980. Active stiffness control of a manipulator in Cartesian coordinates. Proceeding of the IEEE International Conference on Decision and Control including the Symposium on Adaptive Processes, Dec. 1980, IEEE Computer Society, USA., pp: 95-100. DOI: 10.1109/CDC.1980.272026

Siciliano, B. and L. Villani, 1999. Robot Force Control. 1st Edn., Kluwer Academic Publishers, Boston, ISBN: 0-7923-7733-8, pp: 146.

Siciliano, B. and L. Villani, 2000. Parallel force and position control of flexible manipulators. IEEE Proc. Control Theory Appli., 147: 605-612. DOI: 10.1049/ip-cta:20000730

Siciliano, B. and O. Khatib, 2008. Springer Handbook of Robotics. Springer Berlin Heidelberg, ISBN: 978-3-540-23957-4, pp: 1611.

Slotine, J.J.E. and W. Li, 1991. Applied Nonlinear Control. Prentice Hall, ISBN: 0-13-040890-5, pp: 461.

Soichi, N., R. Ikeura, T. Wasaka, K. Mizutani and H. Sawai et al., 2008. A study on impedance control using passive elements for human-assist system. Proceeding of the SICE Annual Conference, Aug. 20-22, Tokyo, pp: 1905-1909. DOI: 10.1109/SICE.2008.4654972

Volpe, R. and P. Khosla, 1995. Equivalence of second-order impedance control and proportional gain explicit force control. Int. J. Robot. Res., 14: 574-589. DOI: 10.1177/027836499501400604

Whitney, E., 1987. Historical perspective and state of art in robot force control. Int. J. Robot. Res., 6: 3-14. DOI: 10.1177/027836498700600101 
Yabuta, T., A.J. Chona and G. Beni, 1988. On the asymptotic stability of the hybrid position/force control scheme for robot manipulators. Proceeding of the IEEE International Conference on Robotics and Automation, Apr. 24-29, IEEE Computer Society, Philadelphia, PA, pp: 338-343. DOI: 10.1109/ROBOT.1988.12071

Yoshikawa, T., 2000. Force control of robot manipulators. Proceeding of the IEEE International Conference Robotic Automation, Apr. 24-28, IEEE Computer Society, San Francisco, CA, USA, pp: 220-226. DOI: 10.1109/ROBOT.2000.844062
Yoshikawa, T., 2003. Dynamic hybrid position/force control of robot manipulators-Description of hand constraints and calculation of joint driving force. IEEE J. Robot. Automat., 3: 386-392. DOI: 10.1109/JRA.1987.1087120

Zheng, G. and A. Hemami, 1997. An overview of robot force control. Robotica, 15: 473-482. DOI: 10.1017/S026357479700057X 